\title{
MORPHOLOGICAL ANALYSIS OF THE ENAMEL ORGAN IN RATS TREATED WITH FLUOXETINE
}

\author{
Igor Henrique Morais Silva, ${ }^{\mathrm{I}}$ Jair Carneiro Leão, ${ }^{\mathrm{I}}$ Liriane Baratella Evêncio, ${ }^{\mathrm{II}}$ \\ Stephen Ross Porter, ${ }^{\mathrm{III}}$ Raul Manhães de Castro ${ }^{\mathrm{IV}}$
}

doi: 10.1590/S1807-59322010000100010

\begin{abstract}
Silva IHM, Leão JC, Evêncio LB, Porter SR, de Castro RM, Morphological analysis of the enamel organ in rats treated with fluoxetine. Clinics.2010;65(1):61-6.

PURPOSE: Previous studies have evaluated the presence of serotonin in the dental epithelia and mesenchyme during odontogenesis, suggesting its participation in tooth development.

MATERIALS AND METHODS: Here, we used fluoxetine, a selective serotonin re-uptake inhibitor, at a dose of $10 \mathrm{mg} / \mathrm{kg}$, administered for $20 \mathrm{days}$ during pregnancy in 12 Wistar rats to examine the influence of this drug on the development of the enamel organ of the upper first molars of rat fetuses at 17 days of intra-uterine life (i.u.l.), and at one, five and ten days postpartum. The pregnant rats were anesthetized with xylazine at $10 \mathrm{mg} / \mathrm{kg}$ and ketamine at $25 \mathrm{mg} / \mathrm{kg}$. The fetuses were removed and beheaded; their jaws were removed, and the upper jaws were exposed. The tissues were fixed in Bouin's fixative, decalcified in 5\% nitric acid for $4-12 \mathrm{~h}$, conventionally processed for microscopy, and embedded in paraffin. Serial sections of approximately $5 \mu \mathrm{m}$ were obtained and stained with hematoxylin and eosin, as well as periodic acid-Schiff.

RESULTS AND CONCLUSION: Morphological analysis showed no structural changes in the experimental group compared to the controls, suggesting that, at the dose used, fluoxetine does not interfere with serotonin-mediated development of the enamel organ or the process of amelogenesis.
\end{abstract}

KEYWORDS: Enamel organ; Development; Fluoxetine; Tooth germ; Serotonin.

\section{INTRODUCTION}

Odontogenesis is the result of a complex interaction between two embryogenic tissues, the epithelium of the first gill arch and the ectomesenchyme, which is derived from neural crest cells. The enamel organ is the portion of the germ dental epithelium composed of the external epithelium, internal epithelium, the reticulum star, and the intermediate stratum. From the enamel organ emerges tooth enamel, the organic matrix of which is deposited by ameloblastic cells through a process called amelogenesis. ${ }^{1-3}$ One hypothesis

\footnotetext{
${ }^{\text {I }}$ Universidade Federal de Pernambuco, Departamento de Clínica e Odontologia Preventiva - Recife/PE, Brazil.

II Universidade Federal de Pernambuco, Departamento de Embriologia e Histologia - Recife, Pernambuco/PE, Brazil.

III Eastman Dental Institute for Oral Health Care Sciences, Oral Medicine Unit - London, UK.

${ }^{\text {IV }}$ Universidade Federal de Pernambuco, Departamento de Nutrição, Recife/ PE, Brazil.

Email: jleao@ufpe.br

Tel: 55812126.8818

Received for publication on August 20, 2009

Accepted for publication on October 08, 2009
}

suggests that one function of neurotransmitters during development results from their early presence during the stages of embryogenesis-regulating events, such as during the first cell division after fertilization, gametogenesis, morphogenesis, migration, and cell differentiation in different tissues. ${ }^{4,5}$ When neurotransmitters interact with their receptors, they alter cell metabolism, influencing various stages of organic development., ${ }^{4,6}$ The serotonin system stands out among the neurotransmitter systems involved in the modulation of development and growth, promoting regulation of epithelial-mesenchymal interactions, encouraging migration and cell differentiation during the formation of branchial neural tubes and arches, and fostering the appearance of different tissues, including the teeth. ${ }^{7-11}$

Discovery of the presence of serotonin (5-HT) within dental mesenchyme ${ }^{9}$ and epithelia ${ }^{12}$ supported the hypothesis that serotonin participates in tooth development. The presence of serotonin receptors (5-HT2A, 5-HT2B, and 5-HT2C) during the development of the tooth germ and other embryogenic tissues was confirmed, supporting the hypothesis of participation of serotonin in odontogenesis. ${ }^{13}$ 
Serotonin has a direct effect on tooth morphogenesis, mediated by intracellular uptake and/or activation of 5-HT1A and 5-HT3 receptors. Serotonin receptors, including 5-HT1A, were found both at the button and bell phases. ${ }^{14-16}$ The activity of 5-HT is the primary contributing factor to regulation of extracellular levels of serotonin and therefore, of serotonergic neurotransmission. ${ }^{17,18}$

Based upon the evidence of involvement of 5-HT in the development of dental enamel, we evaluated the morphology of the enamel organ during odontogenesis in rats treated with fluoxetine.

\section{MATERIALS AND METHODS}

We used albino Wistar rats from the Department of Nutrition at the Federal University of Pernambuco. The animals received a standard vivarium diet (LABINA Purina do Brasil S/A) and water ad libitum. They were kept in rooms at $23 \pm 2{ }^{\circ} \mathrm{C}$, with $12: 12 \mathrm{~h}$ night and dark cycles (clear 06:00 to 18:00 $\mathrm{h}$ and dark from 18:00 to 06:00 h). To obtain newborns, animals were mated in the proportion of one male to two females. Once the presence of sperm was detected, the female was considered pregnant and this day was considered as day zero of the pregnancy. The females were divided into two study groups: the experimental group was treated daily with fluoxetine hydrochloride at $10 \mathrm{mg} / \mathrm{kg}$ in a volume of $10 \mu \mathrm{l} / \mathrm{g}$ of weight, by subcutaneous injection from the 1st to the 20th day of gestation. The control group was treated with a $0.9 \%$ saline solution using the same protocol established for the experimental group. The drug was administered daily between 7 and 8 am.

Morphological analysis of the enamel organ was performed on the upper first molar of fetuses of rats at 17 days i.u.l., and the first, fifth and tenth days of life. For observation of the enamel organ at this age, 3 fetuses were used for observation, totaling 12 animals for each study group. The animals were previously anesthetized by intra-peritoneal injection of atropine $(10 \mathrm{mg} / \mathrm{kg})$, followed by 10 minutes of combination of ketamine $(25 \mathrm{mg} / \mathrm{kg})$ and xylazine $(10 \mathrm{mg} /$ $\mathrm{kg}$ ) intra-peritoneally. The animals were anesthetized and beheaded by guillotine, followed by exposure and removal of the mandible and maxilla. The material was fixed in Bouin solution for 48 hours at room temperature, and subsequently decalcified in an aqueous solution of 5\% nitric acid for $4-$ 12 hours, depending on age of the animal; this process was followed by light microscopy procedures.

Serial $5-\mu \mathrm{m}$ thick histological sections were produced. The specimens were stained with hematoxylin and eosin (HE) and periodic acid-Schiff (PAS) and observed using a light microscope. For morphological analysis of the enamel organ, a one-way analysis of seed development was obeyed.
All dental germs were analyzed from the region close to the primitive oral epithelium - a region of the stem or adjacent to it- to the internal region of the epithelium. Cellular components of each region of the enamel organ, in addition to their structural characteristics, such as the development phase, the cellular form, color, continuity cell, cell type, position of the nucleus, the presence of mitotic figures and blood vessels, basal layer, and deposition of enamel matrix, were all observed in detail.

This study protocol was approved by the Ethics Committee on Animal Experiments of the Center for Biological Sciences, Federal University of Pernambuco (EAEC-UFPE), Recife, Brazil.

\section{RESULTS}

We did not observe any cases of tooth agenesis in the experimental group or the controls, and the developmental chronology was consistent from the tooth germ to the final phase of the crown. The teeth germs were united with the oral epithelium by pedicles at the hood of fetuses at the $17^{\text {th }}$ day i.u.l. in both the experimental group and controls, (Fig. 1a, 1b). Clear condensation of the ectomesenchyme surrounding all teeth germs was seen, as it was below the concavity of the enamel organ, characterizing formation of the dental follicle and the dental papilla, respectively. The enamel organ was well defined-formed by external epithelium, the reticulum star, and internal epitheliumand delimited from the ectomesenchyme by a clear and continuing basement membrane that surrounded the enamel organ from the region of the pedicle to its concavity (see Figs. $1 \mathrm{c}$ and $1 \mathrm{~d}$, particularly the PAS-stained samples). The external epithelium was present as a continuous layer of prismatic low cells with oval nuclei, most clearly observed in the region near the pedicle. The reticulum star was in an early stage of development, with the appearance of intercellular spaces, which were more discreet on the periphery and more common in the central region, with varied cell morphology and mitotic figures. The external epithelium remained with the internal epithelium, and was characterized by the presence of a continuous layer of prismatic low cells with oval nuclei. Mitotic figures were observed along the path of the epithelium of the enamel organ (Figs. 1a, 1b).

Teeth germs were observed at the crowns on the first postpartum day (Figs. 2a, 2b) in the experimental group and controls. This observation was also seen on the $10^{\text {th }}$ day postpartum (Figs. 4a, 4b). The presence of bone surrounding the tooth germ in development tissue was observed, characterizing formation of the alveolar bone crypt, and housing the tooth germ in its interior. Closure 


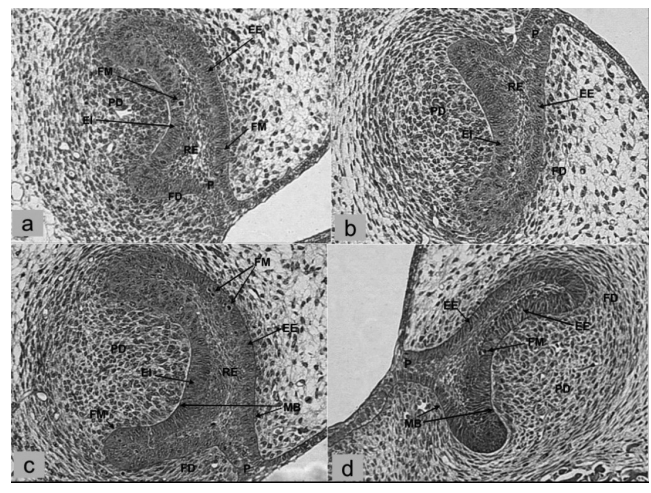

Figure 1 - Photomicrograph of the first molar tooth germ in rats at 17 days i.u.l. in the experimental (a, c) and control (b, d) groups. Pedicle (P); external epithelium (EE); star reticulum (RE); internal epithelium (EI); dental papilla (PD); basal membrane (MB); dental follicle (FD); figures of mitosis (FM). Staining: HE, 100 $\times$ in panels a and b; PAS, 100x in panels $\mathrm{c}$ and $\mathrm{d}$

of the crypt occurred first in the tooth germ of the control group, compared to animals treated with fluoxetine. At the crown, the enamel organ was well defined, formed by the internal and external epithelium and the reticulum star. The external epithelium consisted of a discontinuous layer of prismatic and low cells, bounded by the reticulum star in the region of the pedicle. The reticulum star was formed by cells of 'starry' morphology and wide intercellular spaces. In the discontinuous spaces of the external epithelium, we observed many blood vessels from the dental follicle toward the reticulum star. Adjacent to the reticulum star, juxtaposing the cells of the internal epithelium, was a thin and continuous layer of flat cells that contained an intermediate stratum. In the concavity of the enamel organ, there was a continuous

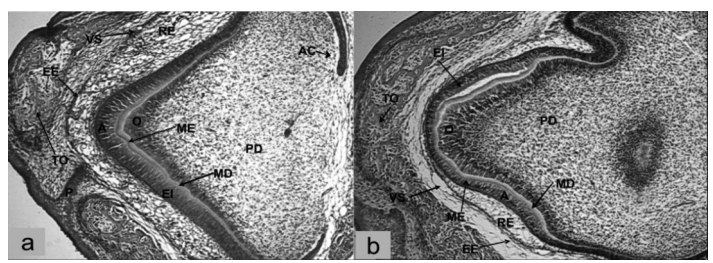

Figure 2 - Photomicrograph of part of the first molar tooth germ in rats at 1 day postpartum in the experimental (a) and control (b) groups. Pedicle (P); bone tissue (TO); external epithelium (EE); star reticulum (RE); internal epithelium (EI); ameloblastic (A); enamel matrix (ME); dentin matrix (MD); odontoblasts (O); cervical loop (AC); dental papilla (DP). Staining: HE, 40×

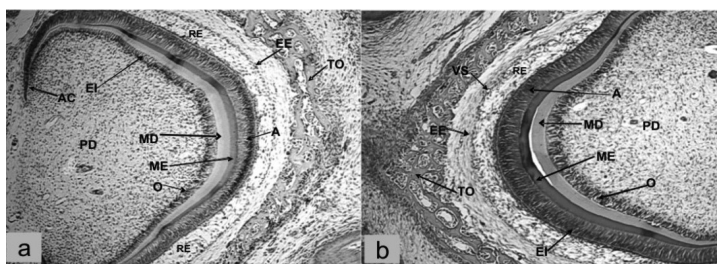

Figure 3 - Photomicrograph of part of the first molar tooth germ in rats at 5 days postpartum in the experimental (a) and control (b) groups. Bone tissue (TO); external epithelium (EE); star reticulum (RE); ameloblastic (A); enamel matrix (ME); blood vessel (VS); dentin matrix (MD); odontoblasts (O); cervical loop (AC); dental papilla (PD). Staining: HE, 40× layer of cells with different characteristics when observed from the future region of the cusp, toward the region of the cervical loop. In the future cusp, ameloblastic cells were observed as high prismatic cells arranged on the deposited enamel matrix, with nuclei facing the intermediate stratum. Continuing from the equivalent region of the future cusp toward the neck strap, the pre-ameloblastic cells presented in a prismatic core, with their nuclei facing the intermediate stratum. More apically, the cells of the internal epithelium were seen as low cells with basal nuclei toward the papilla cells (Figs. 2a, 2b; 3a, 3b).

In the teeth germs from animals at 10 days postpartum, the internal epithelium was composed of ameloblastic cells along most of its length and was seen as high prismatic cells with nuclei facing the intermediate stratum. The reticulum star involuted and was interconnected with the external epithelium, making it difficult to see. The deposited enamel matrix was thick and involved almost all of the teeth germs in development. Clear Tomes' processes were present in the region closer to the ameloblastic cells. The amount of dentine matrix deposited varied by tooth germ. Internally, in the dentine, there were odontoblasts with cytoplasmic extensions, known as Tomes' fibrils, toward the dentine matrix, (Figs. 4a, 4b).

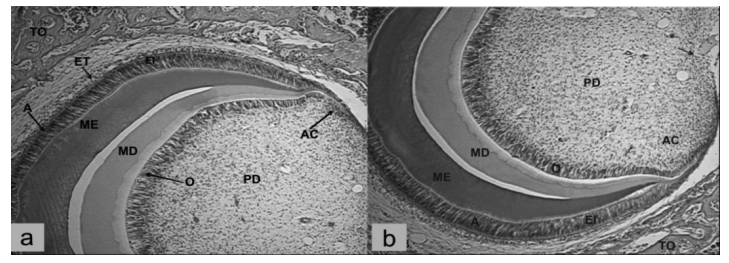

Figure 4 - Photomicrograph of part of the first molar tooth germ in rats at 10 days postpartum in the experimental (a) and control (b) groups. Bone tissue (TO); internal epithelium (EI); ameloblastic (A); enamel matrix (ME); odontoblasts (O); dentin matrix (MD); dental papilla (PD); neck strap (AC). Staining: HE, $40 \times$

\section{DISCUSSION}

From our observations of the evolution of the enamel organ at each age, it appeared that its development occurred without morphological change as compared to the control group. From the 17th day i.u.l., we observed germ tissue at the hood, with regions of the enamel organ bounded in both groups with the same structural characteristics. As the development of the tooth germ typically occurs until the stage of the crown or bell, the development advanced in animals at one, five and ten days postpartum, with appropriate characteristics for each stage of odontogenesis. ${ }^{2,3}$

From the first postpartum day, deposition of enamel and the dentine matrix occurred in the future region of the cusp of the tooth; this process was similar in the experimental and control groups. We observed that amelogenesis occurred in both study groups without morphological differences that 
might affect the future structure of the mature dental enamel. The fact that tooth-germ development was similar between the groups at the stages of the hood and bell suggests that the processes of morphodifferentiation and histodifferentiation occurred normally, despite drug administration. The tooth germ developed all elements of the future tooth crown; histodifferentiation occurred, thereby allowing cells to secrete the dental tissues, especially the enamel. ${ }^{19,20}$ During differentiation of internal epithelium to ameloblastic cells, the cells in the concavity of the enamel organ retained the same structural characteristics, indicating that the synthesis and maturation of the enamel occurred normally. ${ }^{2,3}$

At the start of the deposition of the dentine matrix, around the first day postpartum in both study groups, the enamel remained, with the development of an involutive process, characterized by an external discontinuity of the epithelium, vascular invasion, and collapse of the reticulum star.

The involutive process of the enamel organ occurred with deposition of the enamel matrix. The evolution of amelogenesis caused changes in the characteristics of the regions that make the enamel organ. ${ }^{21,22}$ The discontinuity of the external epithelium and the presence of blood vessels in contact with it in animals at one and five days postpartum in both study group indicate the existence of the involutive process of the reticulum star in the enamel organ in the investigated teeth germs. Thus, there was no change that suggested impairment of the evolution of amelogenesis in animals in either study group.

The beginning of secretion of the enamel matrix begins after deposition of the mantle dentine, after disappearance of the basement membrane located between the preameloblastic cells and the odontoblasts. This process allows contact between the dentine matrix and the pre-ameloblastic cells and their differentiation into ameloblastic cells. ${ }^{23,24}$ In both study groups, it was possible to observe the basement membrane surrounding the enamel organ in animals at 17 days i.u.1., including its fold feature, when sections were stained with PAS. In animals at 1 day postpartum, the basement membrane was not seen, but enamel and dentine matrix were already deposited at this age. The existence of basement membrane in both groups of animals at 17 days i.u.l. and its absence in animals at 1 day postpartum suggest that there was no difference in the start of amelogenesis between the animals in the two study groups. Thus, fluoxetine, at the dose used in this study, apparently had no influence on the start of amelogenesis.

Differences with regard to the closure of the crypt and the absence of pedicle bone were observed between the experimental group and controls. In animals in the control group, the bone crypt was already closed by the first postpartum day, with the tooth germ inside its bone crypt, without contact with the oral epithelium. In the experimental group, the bone crypts of the animals at the first day postpartum had not yet closed, a phenomenon that was observed only in the animals at five days postpartum. While it was not the objective of this study, we did observe that there was a delay in closing of the crypt bone in animals treated with fluoxetine. These findings suggest that fluoxetine interfered with the development of crypt alveolar bone and influenced the mechanism of tooth eruption. However, our methodology did not allow for any conclusion about the influence of fluoxetine during the eruption of the developing tooth or in the periodontium.

In tooth development, serotonin appears to stimulate odontogenesis by interacting with different serotonin receptors ${ }^{13}$ expressed in the epithelium and dental mesenchyme during odontogenesis ${ }^{9}$ and through sites of 5-HT uptake present in the tooth germ during development. ${ }^{14}$ The administration of fluoxetine in pregnant rats can alter the levels of available serotonin, making it possible to study its influence on tooth development, which, in turn, results from important epithelial-mesenchymal interactions ${ }^{3}$. In this study, the administration of fluoxetine at $10 \mathrm{mg} / \mathrm{kg}$ showed no morphological changes in the enamel organ in the first molars that could impair the development of amelogenesis. Little information is available in the literature about the role of serotonin in tooth development, especially regarding its relationship with the development of the enamel organ in amelogenesis.

Assuming that serotonin has a stimulatory role in the development of teeth, ${ }^{12,14}$ it is possible that the dose used in our study was insufficient to cause changes in the development of the enamel organ. The fact that amelogenesis occurred without morphological changes in the enamel organ suggests that the stimulatory action of serotonin occurred, ${ }^{12}$ but the changes in the level caused by the administration of the drug did not promote morphological changes during amelogenesis.

We found no evidence that fluoxetine, at the dose used, interfered with development of the enamel organ. However, studies using higher doses of fluoxetine are needed to confirm the safety of this drug during pregnancy, with respect to the development of teeth, especially amelogenesis.

\section{CONCLUSIONS}

Based on the results presented here, we found no morphological changes in the enamel organ of the teeth germs of the upper first molars of rat fetuses treated with $10 \mathrm{mg} / \mathrm{kg}$ of fluoxetine during pregnancy. Its use did not cause tooth agenesis or changes in the chronology of toothgerm development at the ages of animals studied. 


\section{REFERENCES}

1. Beeman CS, Kronmiller JE. Temporal distribution of endogenous retinoids in the embryonic mouse mandible. Arch. Oral Biol.1994;39:7339.

2. Miletich I, Sharpe PT. Human Molecular Genetics Review. 2003;12:16270 .

3. Katchburian E, Arana-Chavez VE. Histologia e embriologia oral. 2. ed. São Paulo-SP: Panamericana; 2004.p. 237.

4. Buznikov GA, Shmukler YB, Lauder JM. From oocyte to neuron: do neurotransmitters function in the same way throughout development? Review Cell Mol Neurobiol. 1996;16 :537-59.

5. Buznikov GA, Lambert HW., Lauder JM. Serotonin and serotonin-like substances as regulators of early embryogenesis and morphogenesis. Review Cell Tissue Res.2001;305: 177-86.

6. Lauder JM, Wallace JA. Krebs H. Roles for serotonin in neuroembryogenesis. Adv. Exp. Med. Biol.1981;133:477-506.

7. Shuey DL, Sadler TW, Tamir H, Lauder JM. Serotonin as a regulator of morphogenesis: site specific malformations following exposure to serotonin uptake inibitors. Teratology.1992;46:367-78.

8. Turlejsky K. Evolutionary ancient roles of serotonin: long-lasting regulation of activity and development. Acta Neurobiologiae Experimentalis.1996;56:619-36.

9. Lauder JM, Zimmerman EF. Sites of serotonin uptake in epithelia of the developing mouse palate, oral cavity and face: possible role in morphogenesis. J. Craniofac. Gen. Dev. Biol.1988;8:265-76.

10. Byrd KE, Yang L, Yancey KW, Teomim D, Domb AJ. Increased in vivo levels of neurotransmitters to trigeminal motoneurons: effects on craniofacial bone and TMJ. Anatom. Rec.2000;258:369-83.

11. Moiseiwitsch JRD. The role of serotonin and neurotransmitters during craniofacial development. Crit. Rev. Oral Biol.2000;11:230-9.

12. Moiseiwitsch JRD, Lauder JM. Stimulation of murine tooth development in organotypic culture by the neurotransmitter serotonin. Arch Oral Biol.1996;41:161-5.
13. Lauder JM, Wilkie MB, Wub C, Singh S. Expression of 5-HT2A, 5-HT2B and 5-HT2C receptors in the mouse embryo. Int. J. Dev. Neuroscience.2000;18:653-62.

14. Moiseiwitsch JRD, Raymond JR, Tamir H, Lauder JM. Regulation by serotonin of tooth-germ morphogenesisand gene expression in mouse mandibular explant cultures. Arch. oral biol.1998;43:789-800.15.

Tecott L, Shtrom S, Julius D. Expression of a serotonin-gated ion channel in embryonic neural and noneural tissues. Mol. Cell neuroscience. $1995 ; 6: 43-55$.

16. Johnson DS, Heinemann SF. Embrionic expression of the $5-\mathrm{HT}_{3}$ receptor subnit, 5-HT ${ }_{3} \mathrm{R}-\mathrm{A}$, in the rat: an in situ hybridization study. Mol. Cell neuroscience.1995;6:122-38.

17. Blakely RD, Berson HE, Fremeau RTJR, Caron MG, Feek MM, Prince $\mathrm{HK}$, et al. Cloning and expression of a functional serotonin transporter from rat brain. Nature. 1991; 354:66-70.

18. Hoffman BJ, Hansson SR, Mezey E, Palkovits M. Localization and dynamic regulation of biogenic amine transporters in the mammalian central nervous system. Front. Neuroendocrinol. 1998;19:187-231.

19. Reith EJ. The ultrastructure of ameloblasts during matrix formation end the maturation of enamel. J. Biophys. Biochem. Cytology.1961;9:825-39.

20. Kallenbach E. Fine estructure of rat incisor ameloblasts during enamel maturation. J. Ultrasctruct. Res.1968;22:90-119.

21. Addison WHF, Appleton JL. The vascularity of the enamel organ in the developing molar of the albino rat. Am. J. Anat.1922;31:167-89.

22. Baratella L, Arana-Chavez VE, Katchburian E. Macrophages and apoptosis in the stellate reticulum of the rat enamel organ. J Anat. 2000;197:303-6.

23. Katchburian E, Holt SJ. Studies on the development of the amelobasts. I- fine structure. J. Cell Sci.1972;11:415-47.

24. Katchburian E, Burgess AMC. Fine structure of contacts and between ameloblasts in rat tooth germ. Arch. Oral Biol.1977;22:551-3. 
